\title{
Elevated Circulating Interleukin-27 in Patients with Coronary Artery Disease Is Associated with Dendritic Cells, Oxidized Low-Density Lipoprotein, and Severity of Coronary Artery Stenosis
}

\author{
Wen Jin, ${ }^{1}$ Yiqiao Zhao, ${ }^{1}$ Wen Yan, ${ }^{2}$ Longxing Cao, ${ }^{3}$ Weiwei Zhang, ${ }^{3}$ Ming Wang, ${ }^{4}$ Ting Zhang, \\ Qiang Fu, ${ }^{3}$ and Zhiliang $\mathrm{Li}^{3}$ \\ ${ }^{1}$ Cardiovascular Department, Guangdong No.2 Provincial People's Hospital, Guangdong 510317, China \\ ${ }^{2}$ Oncology Department, Guangdong No.2 Provincial People's Hospital, Guangdong 510317, China \\ ${ }^{3}$ Cardiovascular Department, Zhujiang Hospital, Southern Medical University, Guangdong Province, Guangdong 510282, China \\ ${ }^{4}$ Traditional Chinese Medicine Department, Zhujiang Hospital, Southern Medical University, Guangdong 510282, China
}

Correspondence should be addressed to Qiang Fu, fuqiang020@126.com and Zhiliang Li, lizhiliang020@126.com

Received 12 March 2012; Revised 26 April 2012; Accepted 15 May 2012

Academic Editor: Hidde Bult

Copyright ( 12012 Wen Jin et al. This is an open access article distributed under the Creative Commons Attribution License, which permits unrestricted use, distribution, and reproduction in any medium, provided the original work is properly cited.

\begin{abstract}
Coronary artery disease (CAD) is an immune-mediated chronic inflammatory disease mainly caused by atherosclerosis. The aims of this study were to investigate the role of interleukin-27 (IL-27) in patients with CAD and the severity of coronary artery lesions, which was evaluated by Gensini score and to investigate the biosynthesis of IL-27 and oxidized low-density lipoprotein (ox-LDL) in vitro using monocyte-derived dendritic cells (DCs). To this aim, plasma levels of IL-27, ox-LDL, and Gensini score were analyzed in patients with CAD $(n=136)$ and normal subjects (controls, $n=29)$. IL-27 concentration of the supernatant and the mRNA expression levels of p28 and ebi3, subunits of IL-27, from cultured immature DCs incubated with different concentrations of oxLDL for $24 \mathrm{~h}$ were also analyzed. We found that circulating IL-27 levels were significantly elevated in patients with CAD than in controls $(P<0.01)$, and positively correlated to ox-LDL and Gensini score. ox-LDL dose-dependently upregulated expression of both IL-27 protein and IL-27 (p28 and EBI3) mRNA in vitro, indicating that ox-LDL can stimulate DCs to produce IL-27. These results demonstrate that IL-27 might regulate the network of immunity and inflammation in the pathogenesis of atherosclerosis.
\end{abstract}

\section{Introduction}

Coronary artery disease (CAD) remains the leading cause of death worldwide despite advances in prevention and treatment [1]. Additional insight into the mechanisms of the development of atherosclerosis and the underlying cause of CAD is needed to improve treatment outcomes of these patients. Particularly the contribution of immune responses with cumulating evidence suggests that atherosclerosis is a chronic immune-inflammatory disease [2].

Dendritic cells (DCs), most efficient antigen-presenting cells in the immune system, have emerged as key players in initiating and regulating adaptive immune responses [35]. Current research has recognized dendritic cells as key initiators and regulators of immune processes in atherosclerosis $[6,7]$. DCs can modulate immune responses by a variety of mechanisms in the pathogenesis of atherosclerosis [8-10]. This includes expression of $\mathrm{T}$ cell costimulatory and regulatory molecules, as well as the production of chemokines and cytokines. The secretion of interleukin-(IL) 12 , IL-10, and other cytokines by DCs plays a critical role in polarizing naive $\mathrm{T}$ cells into $\mathrm{Th} 1, \mathrm{Th} 2$, $\mathrm{T}$ regulatory cells (Treg), or Th17 cells, which are known to drive or dampen inflammatory processes in atherosclerosis [11].

Recently, IL-27, mainly produced by DCs, has been identified as cytokines belonging to the IL-12 family [12] IL-27 is a heterodimeric cytokine composed of EBI-3, a p40related molecule [13], and p28, a p35-related molecule [14]. 
IL-27 receptor complex comprises IL-27R (also called WSX1 or T-cell cytokine receptor) and glycoprotein 130 (gp130) [15]. IL-27R and GP130 are coexpressed on different cell types, such as monocytes, macrophages, DCs, mast cells, NK cells, endothelial cells, and $\mathrm{T}$ and $\mathrm{B}$ lymphocytes [14, 1618] whilst IL-27R is the only known receptor for IL-27 [14]. These may be the molecular basis for the wide-ranging immunomodulatory function of IL-27. Available evidence suggests that IL-27, unlike other members of this cytokine family, has dual function: one as an initiator and the other as an attenuator of immune/inflammatory responses [19].

Given the main effect of IL-27 is the regulation of the innate and adaptive immunity, it is most likely to be involved in atherosclerosis. However, little information is known about the role of IL-27 in atherosclerosis. The aim of this study was therefore to assess the levels of IL-27 in plasma of patients with CAD and produced by DCs in vitro stimulated by oxidized low-density lipoprotein (ox$\mathrm{LDL}$ ). We have demonstrated that (1) the circulating levels of IL-27 are elevated in patients with CAD, particularly in ACS, and correlated with ox-LDL and Gensini score; (2) IL-27 can be secreted from human monocyte-derived DCs in response to in vitro stimulation with ox-LDL, indicating an important role for IL-27 in the pathogenesis of atherosclerosis.

\section{Methods and Materials}

2.1. Study Protocol. The study protocol conforms to the principles of the Declaration of Helsinki and was performed with approval of the Ethics Committee of South Medical University. Subjects were selected from individuals who underwent coronary angiography to investigate ischemic heart disease based on clinical indications (typical and atypical chest discomfort) from November 2008 to December 2009. All subjects are Han Chinese. All subjects gave informed consent, both verbally and in writing, for participation in the study, and underwent coronary artery angiography at Zhujiang Hospital of South Medical University before entering the study. Routine blood analyses were performed in our hospital clinical laboratory.

In total, 165 subjects ( 113 men and 52 women, age range from 32 to 84 years with mean age of $62.16 \pm 9.78$ years) were studied. Patients diagnosed with coronary heart disease had to have had at least one severe stenosis $(>50 \%)$ in a major coronary artery, as determined by diagnostic coronary angiography.

The patients were divided into four study groups. The first group included patients with stable angina pectoris (SAP) that had a long-term, stable effort angina that had lasted at least three months and a positive exercise test. The second group included patients with unstable angina pectoris (UAP), as defined by as either angina with a progressive crescendo pattern or angina that occurred at rest without a recent myocardial infarction. In those patients, transient ST-T segment depression and T-wave inversion were often present, but no significant elevation of cardiac enzymes was detected. Patients with acute myocardial infarction (AMI) had typical angina associated with ST-segment elevations in electrocardiogram and/or elevated plasma troponin-I. The fourth group, controls, consisted of patients with normal coronary artery angiographies. In total, we recruited 29 controls, 30 patients with SAP, 56 patients with UAP, and 50 patients with AMI.

Exclusion criteria were established for patients with autoimmune, neoplastic, liver, hematological, or renal diseases, recent surgery or recent trauma, and/or chronic inflammatory conditions. In addition, patients with valvular heart disease, nonischemic cardiomyopathy, and/or cerebrovascular disease were also excluded. Also, patients who took medications, such as immunosuppressive agents, statins, angiotensin-converting enzyme inhibitors, and angiotensin receptor blockers (before enrollment) were also excluded.

\subsection{Detecting Plasma Concentrations of IL-27 or Oxidized Low-Density Lipoprotein (ox-LDL). Prior to coronary ang- iography, blood samples for determination of IL-27 or ox- LDL were collected in EDTA-citrated tubes, centrifuged, and the isolated plasma was stored at $-80^{\circ} \mathrm{C}$ until analysis within 13 months from sampling. Concentrations of IL- 27 (Biolegend, San Diego, USA) or ox-LDL (Calbiochem, San Diego, USA) in plasma were determined at the same time using enzyme-linked immunosorbent assay (ELISA) kits according to the manufacturer's instructions. Concen- trations were calculated by regression analysis of a standard curve.}

\subsection{Determining the Severity of Coronary Artery Stenosis by} Gensini Score. Gensini score was used to evaluate the severity of coronary artery stenosis from coronary angiography [20, 21]. The procedures were carried out as follows. Selective coronary angiography was conducted by two experienced interventional cardiologists blinded with patient's clinical characteristics and biochemical results. The severity of coronary artery stenosis was assessed by quantitative coronary angiography. Gensini score was used to assess the severity of coronary artery stenosis. According to the degree of luminal narrowing and its location, the Gensini score was calculated by assigning a value to each coronary stenosis. Details of Gensini score are as follows: $1-25 \%, 26-50 \%, 51-75 \%, 76-$ $90 \%, 91-99 \%$, and $100 \%$ of coronary luminal narrowing were given scores of $1,2,4,8,16$, and 32 , respectively, which were then multiplied by a factor that represents the importance of the lesion's position in the coronary arterial system: 5 for the left main coronary artery, 2.5 for the proximal segment of the left anterior descending coronary artery (LAD) or the circumflex artery (LCX), 1.5 for midsegment of LAD, 1 for distal segment of the LAD or the posterolateral artery or the obtuse marginal artery or right coronary artery, and 0.5 for all others.

2.4. Isolation of Human Monocyte-Derived DCs and Culture. Peripheral blood mononuclear cells (PBMC) were isolated from buffy coats of healthy donors using Ficoll gradient. Monocytes were isolated and cultured $\left(1.0 \times 10^{6} / \mathrm{mL}\right)$ as previously described using CellGro DC Medium (CellGenix, 
Freiburg, Germany) supplemented with $50 \mathrm{ng} / \mathrm{mL}$ GM-CSF and $50 \mathrm{ng} / \mathrm{mL} \mathrm{IL-4} \mathrm{(Peprotech,} \mathrm{New} \mathrm{Jersey,} \mathrm{USA)} \mathrm{for} 6$ days to obtain immature DCs. For differentiation into mature DCs, immature DCs cells were resuspended at $6 \times$ $10^{5} / \mathrm{mL}$ and further cultured with different concentrations of oxidized low-density lipoprotein in DC medium supplemented with $50 \mathrm{ng} / \mathrm{mL}$ GM-CSF and $50 \mathrm{ng} / \mathrm{mL} \mathrm{IL-4} \mathrm{for}$ $24 \mathrm{~h}$. The supernatants of DC cultures $(24 \mathrm{~h}$ incubation with different concentrations of ox-LDL) were harvested and the concentrations of IL-27 were analyzed using ELISA kits according to the manufacturer's instructions. DCs were used for the following experiments.

2.5. Phenotypic Analysis of DC by Flow Cytometry. DCs were resuspended at $1.0 \times 10^{5}$ cells in $100 \mu \mathrm{L}$ of PBS and incubated for $30 \mathrm{~min}$ at $4^{\circ} \mathrm{C}$ with different fluorescein isothiocyanate- (FITC-) conjugated monoclone antibodies (mAbs) or appropriate isotype controls. After three washes in cold phosphate-buffered saline (PBS) supplemented with $0.5 \%$ of bovine serum albumin (BSA), cells were fixed with $2 \%$ paraformaldehyde in PBS. The following mAbs were used: FITC-anti-CD83, FITC-anti-CD86, and FITCanti-HLA-DR (all from BD Biosciences, USA). Phenotypic data were acquired using a FACScan system (BD Biosciences, USA) and analyzed with Cell Quest software.

2.6. Using Quantitative Real-Time PCR ( $q R T-P C R)$ to Determine the mRNA Expression Levels of p28 and ebi3 in DCs. Immature DCs were stimulated with ox-LDL $(100 \mathrm{mg} / \mathrm{mL})$ for $0,8 \mathrm{~h}, 16 \mathrm{~h}, 24 \mathrm{~h}$, and then collected. Total RNA was extracted from the collected cells using an RNeasy mini kit (Qiagen). Firstly, reverse transcription (RT) reactions were carried out as follows. $1 \mu \mathrm{g}$ aliquots of total RNA were mixed with $1 \mu \mathrm{L}$ of oligo (dT) primers $(0.5 \mathrm{mg} / \mathrm{mL}), 1 \mu \mathrm{L}$ of $10 \mathrm{mM}$ dNTPs, and double-distilled $\mathrm{H}_{2} \mathrm{O}$ to equalize volumes of all samples at $12 \mu \mathrm{L}$. The mixture was heated at $65^{\circ} \mathrm{C}$ for $5 \mathrm{~min}$, quenched on ice, and spun down briefly, and $8 \mu \mathrm{L}$ of master mix was added. The RT master mix consisted of $4 \mu \mathrm{L}$ of $5 \times$ first strand buffer (Invitrogen), $2 \mu \mathrm{L}$ of $0.1 \mathrm{M} \mathrm{DTT}, 1 \mu \mathrm{L}$ of RNase inhibitor (40 units $/ \mu \mathrm{L}$; Invitrogen $)$, and $1 \mu \mathrm{L}$ of Superscript II $(200 \mu \mathrm{L} / \mu \mathrm{L}$; Invitrogen). The reaction was incubated at $42^{\circ} \mathrm{C}$ for $60 \mathrm{~min}$ and then at $70^{\circ} \mathrm{C}$ for $15 \mathrm{~min}$, followed by a $4^{\circ} \mathrm{C}$ soak. To each sample (in a $20 \mu \mathrm{L}$ total volume) $80 \mu \mathrm{L}$ of double-distilled $\mathrm{H}_{2} \mathrm{O}$ was added. $5 \mu \mathrm{L}$ of diluted cDNA was used for each PCR of $25 \mu \mathrm{L}$ volume. The following primers were used: for PCR amplification of the human p28 cDNA, GCT GGC GGC TCA GCC TGT TG (Forward) and AGC AGC TTC CTG GCG AGA TG (Reverse); for human ebi3 cDNA, CAT AAC AGA GCA CAT CAT CAA GCC (Forward) and GCT TGT AAC GGA TCC AGT ACT TCA (Reverse); for human $\beta$-actin cDNA, TGG CAC CCA GCA CAA TGA A (Forward) and CTA AGT CAT AGT CCG CCT AGA AGC A (Reverse).

After that, qRT-PCR was used to determine the levels of mRNA expression. Briefly, cDNA samples converted from $1 \mu \mathrm{g}$ of total RNA were diluted and studied at several concentrations. Diluted cDNA was mixed with a pair of primers $(10 \mu \mathrm{M})$ targeting human $\mathrm{p} 28$, ebi3, or $\beta$-actin
cDNA sequences as described above and with SYBR Green PCR master mix (Applied Biosystem, CA) in a $15 \mu \mathrm{L}$ volume. PCR cycling was as follows: $2 \mathrm{~min}$ at $50^{\circ} \mathrm{C}, 10 \mathrm{~min}$ at $95^{\circ} \mathrm{C}$ for 1 cycle, followed by 40 cycles for $15 \mathrm{~s}$ at $95^{\circ} \mathrm{C}, 1 \mathrm{~min}$ at $60^{\circ} \mathrm{C}$. Dissociation curves were routinely used to demonstrate that there is only one product produced for each reaction.

2.7. Statistical Analysis. Statistical analysis was performed using SPSS software, version 13.0 (SPSS Inc., Chicago, USA). Continuous variables were expressed as mean $\pm \mathrm{SD}$, and categories were expressed as percentages. Data distribution was assessed by the Shapiro-Wilk's test. Variables were compared by One-Way ANOVA or $\chi^{2}$ test. Proportions were compared by $\chi^{2}$ test. Correlation coefficients were assessed by Pearson's product-moment correlation. A $P$ value of less than 0.05 was considered statistically significant.

\section{Results}

3.1. Clinical Characteristics of Patient Cohort. The clinical characteristics and laboratory data of subjects are summarized in Table 1. The age, gender ratio, risk factors, medications, the levels of serum total cholesterol, triglycerides, creatinine, and Leucocyte counts were similar in overall groups. The levels of serum low-density lipoprotein cholesterol are higher in AMI, UAP, and SAP than in control $(P<0.05)$. The levels of serum uric acid are higher in AMI than in UAP, SAP, and control $(P<0.05)$. Differences in the levels of serum cardiac troponin I were observed among all groups $(P<0.001)$.

3.2. Circulating IL-27, ox-LDL, and Gensini Score Levels in $C A D$. The levels of IL-27 and ox-LDL in serum samples from patients with CAD and controls were assessed by ELISA. As shown in Table 2, circulating IL-27 levels were significantly elevated in patients with CAD than in controls $(P<0.01)$. Furthermore, Circulating IL-27 levels were higher in patients with AMI and UAP than in patients with SAP $(P<0.01)$. ox-LDL levels in patients with AMI were significantly higher than in patients with UAP $(P<0.05)$, or SAP $(P<0.01)$, or in controls $(P<0.01)$. The levels of ox-LDL in patients with UAP and SAP were significantly higher than those in controls $(P<0.05)$. The Gensini score was significantly higher in patients with AMI than in patients with UAP $(P<0.05)$, or SAP $(P<0.01)$, or in controls $(P<0.01)$.

3.3. Correlation among Circulating $I L-27, o x-L D L$, and Gensini Score. As shown in Figure 1, circulating IL-27 levels were significantly positively correlated to ox-LDL and Gensini score $(P<0.01)$. Similarly, the levels of ox-LDL were positively correlated with Genisi score $(P<0.01)$. The results indicated that increased IL-27 levels correlated with the severity of coronary artery stenosis.

3.4. IL-27 Secretion by Human Monocyte-Derived DCs in Response to In Vitro Stimulation with Oxidized Low-Density Lipoprotein. ox-LDL has been shown to induce phenotypically mature DCs, with reduced uptake capacity, secreting 
TABLE 1: Clinical characteristics of patient cohort.

\begin{tabular}{|c|c|c|c|c|c|}
\hline & Control & SAP & UAP & AMI & $P$ \\
\hline Age (years) & $63.793 \pm 8.381$ & $60.767 \pm 10.553$ & $62.232 \pm 10.322$ & $61.960 \pm 9.583$ & 0.700 \\
\hline Male gender, $n(\%)$ & $21(72.414)$ & $21(70)$ & $39(69.643)$ & $32(80)$ & 0.865 \\
\hline \multicolumn{6}{|l|}{ Risk factors, $n(\%)$} \\
\hline Hypertension & $9(31.034)$ & $9(30)$ & $20(35.714)$ & $11(22)$ & 0.493 \\
\hline Current smoking & $12(41.379)$ & $16(53.333)$ & $25(44.643)$ & $20(40)$ & 0.691 \\
\hline Diabetes mellitus & $5(17.241)$ & $7(23.333)$ & $12(21.429)$ & $13(26)$ & 0.836 \\
\hline \multicolumn{6}{|l|}{ Medication, $n(\%)$} \\
\hline Ca-antagonist & $4(13.793)$ & $6(20)$ & $10(17.857)$ & $7(14)$ & 0.868 \\
\hline Aspirin & $7(24.138)$ & $10(30.303)$ & $18(32.143)$ & $20(40)$ & 0.547 \\
\hline$\beta$-blockers & $5(17.241)$ & $4(13.333)$ & $8(14.286)$ & $6(12)$ & 0.933 \\
\hline Other antiplatelet agents & $2(6.897)$ & $3(10)$ & $7(12.5)$ & $12(24)$ & 0.132 \\
\hline TC (mmol/L) & $5.188 \pm 1.271$ & $4.807 \pm 1.196$ & $4.875 \pm 1.229$ & $4.885 \pm 1.166$ & 0.618 \\
\hline LDL-C (mmol/L) & $2.387 \pm 0.669$ & $2.918 \pm 1.000^{\mathrm{a}}$ & $2.798 \pm 0.682^{\mathrm{a}}$ & $2.916 \pm 0.871^{\mathrm{a}}$ & 0.029 \\
\hline $\mathrm{TG}(\mathrm{mmol} / \mathrm{L})$ & $1.292 \pm 0.636$ & $1.311 \pm 0.470$ & $1.338 \pm 0.528$ & $1.398 \pm 0.544$ & 0.830 \\
\hline Leukocytes (G/L) & $7.060 \pm 1.491$ & $7.664 \pm 2.031$ & $7.193 \pm 1.877$ & $7.138 \pm 2.042$ & 0.587 \\
\hline Creatinine $(\mu \mathrm{mol} / \mathrm{L})$ & $89.931 \pm 20.664$ & $98.100 \pm 19.744$ & $95.750 \pm 16.282$ & $94.620 \pm 18.951$ & 0.380 \\
\hline Uric acid $(\mu \mathrm{mol} / \mathrm{L})$ & $283.830 \pm 95.354$ & $324.730 \pm 111.372$ & $312.930 \pm 108.287$ & $334.500 \pm 75.393^{\mathrm{a}}$ & 0.161 \\
\hline$c \operatorname{TnI}(\mu \mathrm{g} / \mathrm{L})$ & $0.012 \pm 0.004$ & $0.017 \pm 0.010^{\mathrm{a}}$ & $0.054 \pm 0.112^{\mathrm{a}}$ & $15.572 \pm 16.487^{\mathrm{a}, \mathrm{b}, \mathrm{c}}$ & $<0.001$ \\
\hline
\end{tabular}

Values are expressed as percentages or mean \pm SD.

${ }^{a} P<0.05$ versus control subjects; ${ }^{b} P<0.05$ versus stable angina pectoris patients; ${ }^{\mathrm{c}} P<0.05$ versus unstable angina pectoris patients.

SAP: stable angina pectoris; UAP: unstable angina pectoris; AMI: acute myocardial infarction; TC: total cholesterol; LDL-C: low-density lipoprotein cholesterol; TG: triglycerides; cTnI: cardiac troponin I.

IL-12 [22, 23]. Furthermore, IL-27, a new member of IL12 family, also can be produced by activated dendritic cells, suggesting possible responsiveness to ox-LDL. To investigate a possible role for IL-27 in the proinflammatory effects of ox-LDL, we examined the capacity of ox-LDL to induce IL27 production by DC. Human peripheral blood monocytederived DCs were stimulated with increasing concentrations of ox-LDL (0 to $100 \mathrm{mg} / \mathrm{mL}$ ) and IL-27 expression was quantified by ELISA or its mRNA expression quantified by real-time PCR after $24 \mathrm{~h}$ incubation with ox-LDL. The results showed that ox-LDL upregulated expressions of CD83, CD86, and HLA-DR in DCs in a concentration-dependent manner (Figure 2). IL-27 protein (Figure 3(a)) and IL-27 p28 (Figure 3(b)) and ebi3 mRNA (Figure 3(c)) were expressed in a dose-dependent manner in response to ox-LDL. oxLDL-induced IL-27 p28 mRNA expression peaked at $16 \mathrm{~h}$ (Figure 3(d)), while ebi3 was induced to a much lesser extent and peaked at $8 \mathrm{~h}$ (Figure $3(\mathrm{e})$ ).

\section{Discussion}

CAD is a typically atherosclerotic disease. Recent evidence has indicated that inflammation and immunity, interacting with metabolic risk factors, are involved in mediating all stages of atherosclerosis, from low-density lipoprotein (LDL) cholesterol accumulation within the subendothelial space to atherosclerotic plaque progression, rupture, and thrombosis [24]. An intricate interplay between multiple immunological and biochemical mediators initiates and promotes these progresses.
IL-27 plays a dual role in regulating immune responses with both pro- and anti-inflammatory properties. It promotes the early Th1 differentiation via STAT1-mediated T-bet activation [25], but it suppresses the differentiation to Th2 [26, 27] and Th17 [28, 29] and production of proinflammatory cytokines $[30,31]$, and induces production of anti-inflammatory cytokines such as IL-10 by activated T cells [32].

The role of IL-27 in promoting or suppressing inflammation may vary within different diseases. Currently available evidences show that IL-27 promotes the inflammation in diseases such as experimental crescentic glomerulonephritis [33], experimental hepatitis [34] and colitis [35], systemic sclerosis [36]; but suppresses the inflammation in diseases such as autoimmune arthritis [37], allergic asthma [38, 39], chronic inflammation of the central nervous system [29], experimental autoimmune encephalomyelitis [40-42], intraocular inflammation [43], Leishmania donovani infection [44]. IL-27 promotes early differentiation of TH1 and previous studies demonstrated marked elevations in the percentage of circulating Th1 cells in ACS patients [11]. In this study, we found that circulating levels of IL-27 are elevated in patients with CAD and positively correlated with the degree of the diseases, particularly in ACS, suggesting that IL-27 probably participates in the development of CAD. Further studies have shown that Th1 cells and their related cytokines promote the development and progression of atherosclerosis, whereas Th2 and regulatory T cells, and their related cytokines exert clear antiatherogenic activities [10, 11]. Furthermore, along with these findings, we found that circulating levels of IL-27 were significantly correlated with 


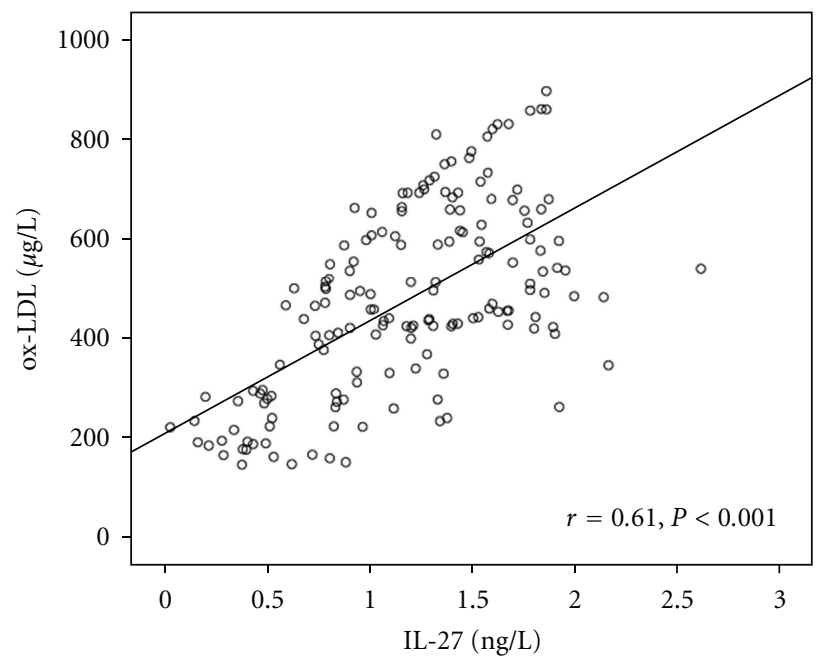

(a)

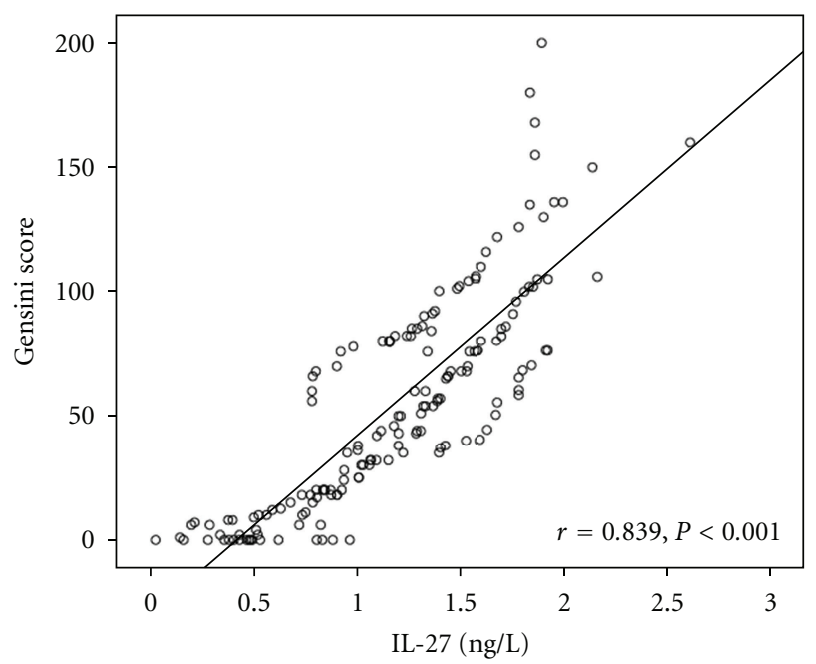

(b)

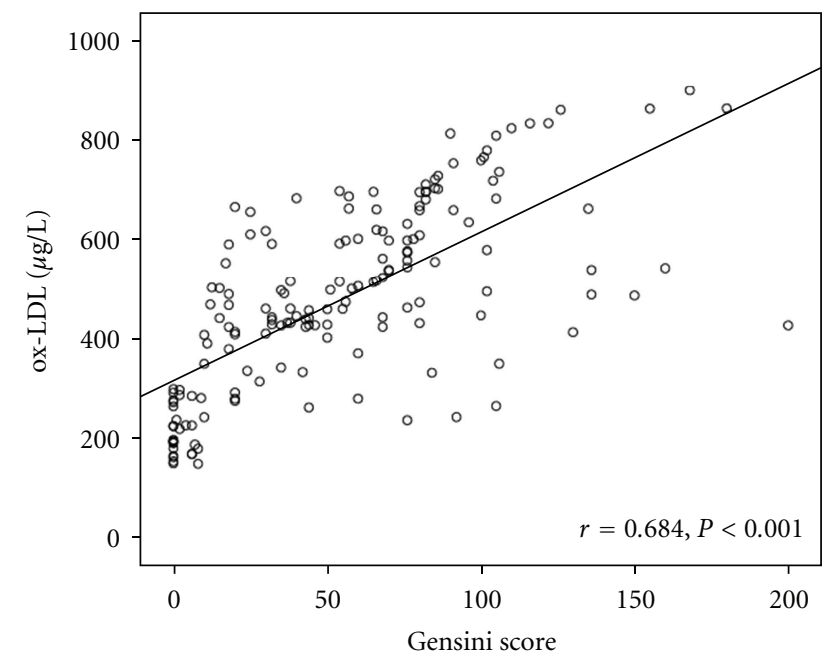

(c)

Figure 1: Correlation analysis of circulating levels of IL-27, ox-LDL, and Gensini score in the overall population. Circulating levels of IL-27 were positively correlated with ox-LDL (a), Gensini score (b); Circulating levels of ox-LDL were positively correlated with Gensini score (c). $r$ : correlation coefficient.

TABLE 2: Circulating IL-27, ox-LDL, and Genisi score of subjects in each group.

\begin{tabular}{|c|c|c|c|c|c|}
\hline & Control & SAP & UAP & AMI & $P$ \\
\hline ox-LDL $(\mu \mathrm{g} / \mathrm{L})$ & $212.310 \pm 48.990$ & $356.810 \pm 84.867^{\mathrm{a}}$ & $539.240 \pm 95.205^{\mathrm{a}, \mathrm{b}}$ & $629.050 \pm 149.541^{\mathrm{a}, \mathrm{b}, \mathrm{c}}$ & $<0.001$ \\
\hline IL-27 (ng/L) & $0.467 \pm 0.235$ & $1.020 \pm 0.383^{\mathrm{a}}$ & $1.401 \pm 0.389^{\mathrm{a}, \mathrm{b}}$ & $1.444 \pm 0.336^{\mathrm{a}, \mathrm{b}}$ & $<0.001$ \\
\hline Genisin score & $2.000 \pm 2.891$ & $39.350 \pm 28.708$ & $62.250 \pm 36.538$ & $85.080 \pm 36.591^{\mathrm{a}, \mathrm{b}, \mathrm{c}}$ & $<0.001$ \\
\hline
\end{tabular}

Values are expressed as mean $\pm \mathrm{SD}$.

${ }^{a} P<0.05$ versus control subjects; ${ }^{b} P<0.05$ versus stable angina pectoris patients; ${ }^{c} P<0.05$ versus unstable angina pectoris patients.

SAP: stable angina pectoris; UAP: unstable angina pectoris; AMI: acute myocardial infarction.

Genisini score which reflects the severity of coronary artery stenosis, indicating that IL-27 may promote the development and progression of CAD by inducing Th1 differentiation and related cytokine production.

A key role of DCs in bridging innate and adaptive immune systems has been recognized as antigen presentation since DCs were discovered $[45,46]$. Upon acquiring "maturation/danger" signals, that is, ox-LDL, cytokines, and other molecules associated with inflammation or tissue damage, immature DCs rapidly undergo differentiation and maturation and migrate along chemotactic gradients to lymphatic tissues, where they form contacts with $\mathrm{T}$ cells to initiate a primary immune response [47]. In DC-T-cell contact, DCs secrete a spectrum of cytokines such as IL-12, 


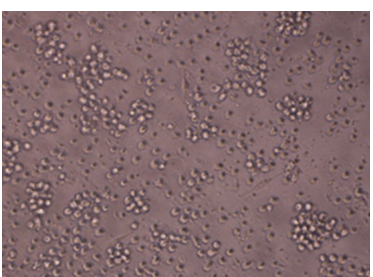

Control

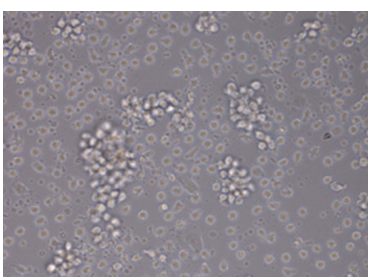

ox-LDL (50 mg/mL)

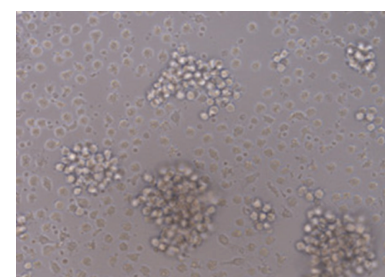

ox-LDL (100 mg/mL)

(a)

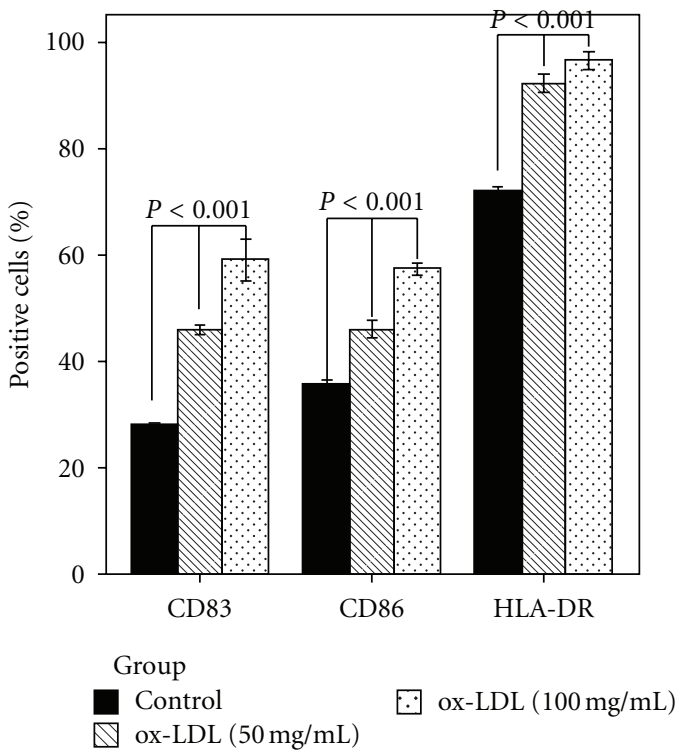

(b)
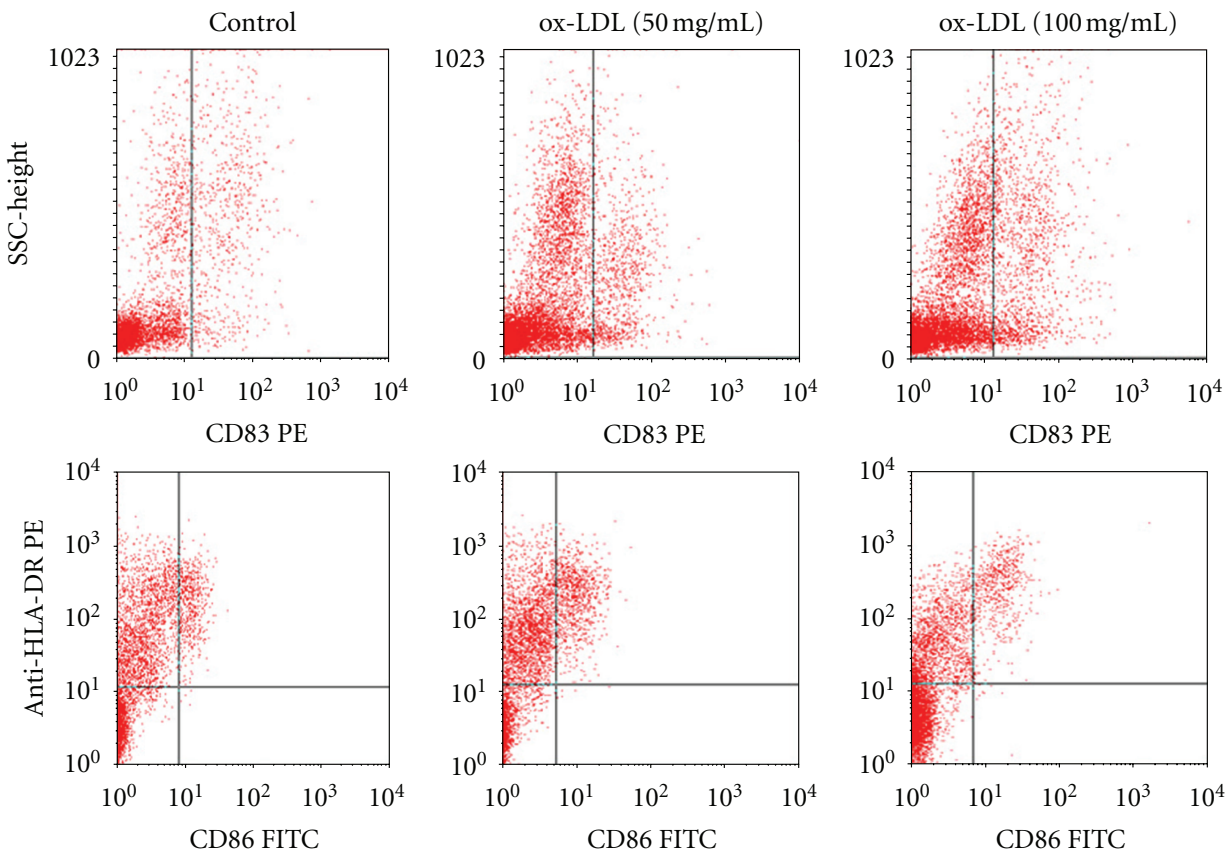

(c)

FIGURE 2: ox-LDL-induced morphological and phenotypic change in monocyte-derived DCs. Immature DCs were treated with different concentrations of ox-LDL in DC medium supplemented with $50 \mathrm{ng} / \mathrm{mL}$ GM-CSF (Peprotech) and $50 \mathrm{ng} / \mathrm{mL}$ IL-4 for $24 \mathrm{~h}$. (a) DCs morphology were visualized by conventional light microscopy. (b) and (c) Cell surface molecules (CD83, CD86, and HLA-DR) were examined by FACS analysis. $P<0.001$ compared among different concentration of ox-LDL-stimulated DCs. 


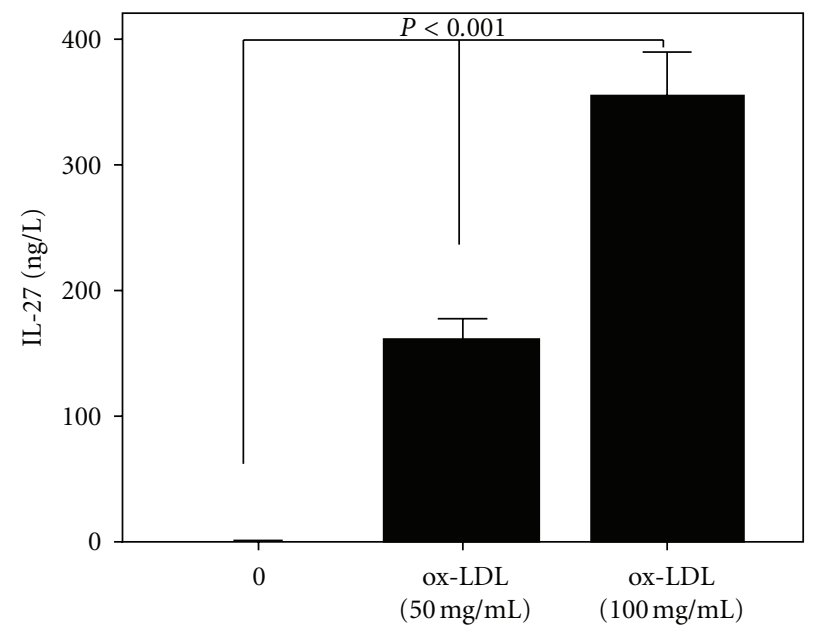

(a)

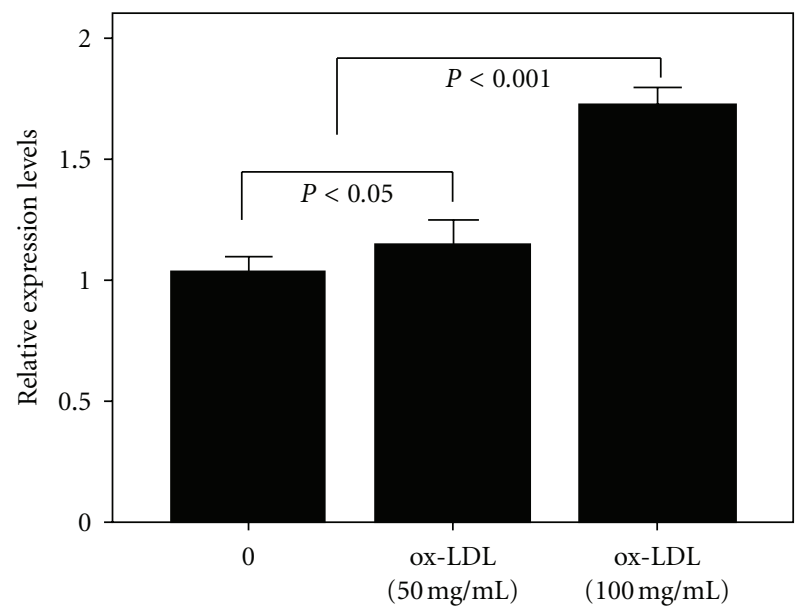

(c)

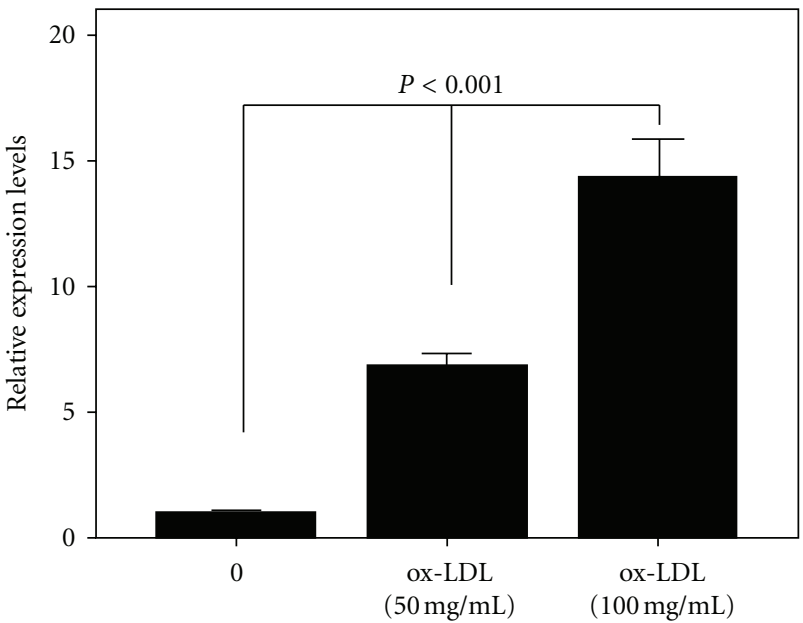

(b)

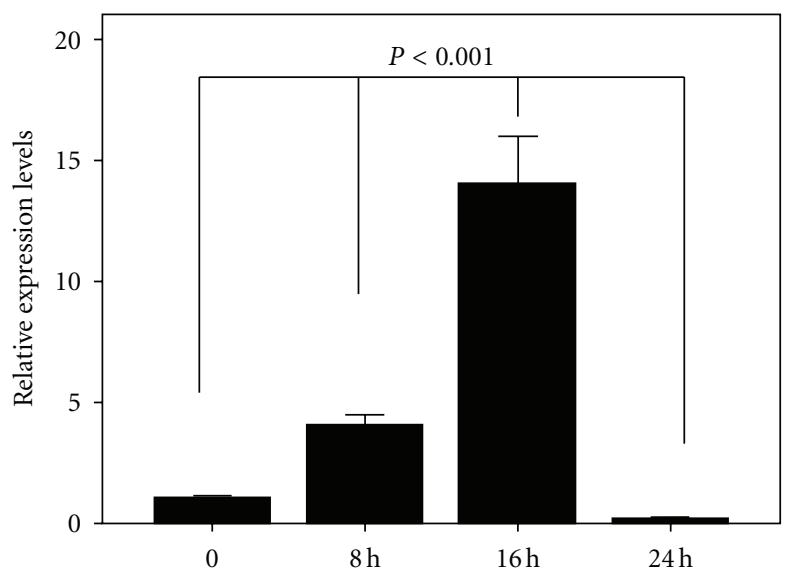

(d)

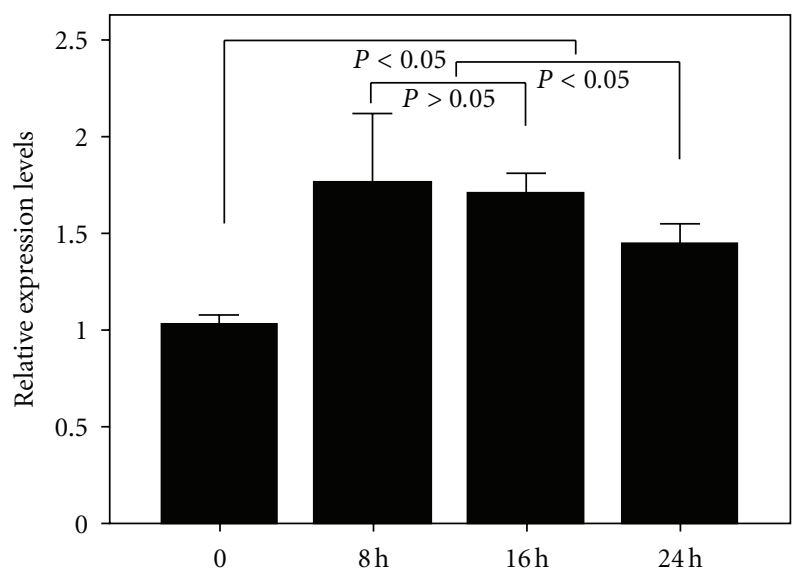

(e)

Figure 3: ox-LDL induced interleukin (IL)-27 production in monocyte-derived DCs. (a) Immature DCs were stimulated with different concentrations of ox-LDL for $24 \mathrm{~h}$. The concentrations of IL-27 were analyzed using ELISA kit. (b) and (c) The mRNA expression levels of IL-27 p28 and ebi3 were evaluated by a real-time PCR analysis. The results are expressed as relative level to the control value. Results shown are means \pm SD of six experiments. (d) and (e) Immature DCs were stimulated with ox-LDL (100 mg/mL) for 0, $8 \mathrm{~h}, 16 \mathrm{~h}$, and $24 \mathrm{~h}$. Then the mRNA expression levels of IL-27 p28 and ebi3 were evaluated by a real-time PCR analysis. The results are expressed as relative level to the control value. Results shown are means \pm SD of six experiments. 
IL-10, and IL-27, which determines their ability to polarize naive T cells into Th1, Th2, T regulatory cells (Treg), or Th17 cells $[3,4]$.

Several studies have demonstrated that mature DCs are upregulated and immature DCs are downregulated in patients with CAD [48-50], even monocytes-derived DCs from CAD patients showed more matured than from controls [48-50]. This study showed reduced counts of activated mDCs in CAD patients. This is possibly due to circulating DCs become activated, leaved the circulation, and migrated to lymphoid organs or to the site of inflammation (atherosclerotic plaques). However, if those activated DCs secrete IL-27 before or after leaving the circulation, the levels of this cytokine will still be elevated in spite of the lower count of activated circulating DCs [50]. ox-LDL can induce the maturation of DCs and activate them to produce cytokines such as IL-12 [22, 23]. Circulating oxLDL is not only an independent predictor for CAD, but also an important atherogenic factor [51-53]. Consistent with previous studies, we observed evidence of a correlation between circulating ox-LDL and the severity of CAD [54]. In addition, we demonstrated that circulating ox-LDL is positively correlated with IL-27, which indicates that ox-LDL may be a major factor activating DCs to produce IL-27. To investigate this possibility, we studied the capacity of ox-LDL to induce IL-27 production by DC. The results showed that ox-LDL was a factor inducing secretion of IL-27 by DCs, suggesting an ox-LDL-induced and DC-mediated Th1-shift of the adaptive immunity.

Furthermore, IL-27 can be found in atherosclerotic plaques [55]. Expression of IL-27 may be closely related to DCs and ox-LDL in atherosclerotic plaques. Available evidence suggests that DCs play an important role in the pathogenesis of atherosclerosis. DCs are commonly found in the arterial intima [56] and have been shown to preferentially accumulate in regions predisposed to atherosclerosis in the normal murine aortic intima where they initiate nascent foam cell lesions at very early stages, as the atherosclerotic plaque starts to develop [57-59]. The uptake of oxLDL by scavenger receptors leads to the accumulation of cholesterol within the foam cells of atherosclerotic lesions and have the effect of demonstrably altering DC function. In advanced atherosclerotic plaques, DCs are mostly present as a mature phenotype and accumulate preferentially within the vulnerable plaque shoulder by colocalizing with $\mathrm{T}$ cells $[60,61]$. Several studies also showed that $\mathrm{Th} 1$ cells play an important role in promoting the progression of atherosclerotic plaques [2, 10, 11]. The number of accumulated DCs is directly parallel to plaque complexity and inflammation $[62,63]$. These reports showed that DCs accumulate in vulnerable plaque shoulders, and are related with plaque complexity are currently questioned and require confirmation or reevaluation [64]. Previous reports were based on a DC marker (fascin) that is expressed by neovascular endothelial cells that are prominently present in those conditions. Moreover, CD83 the marker of mature DCs $[60,63]$ is not DC-specific as it is expressed by lymphocytes and many other leukocytes [64]. Thus, combining the data from this and the previous studies leads to the assumption that in atherosclerotic plaques ox-LDL stimulate DCs to produce IL-27, which in turn further promotes Th1 differentiation. Thus, IL-27 potentially plays an important role in promoting the development and progression of atherosclerosis.

There are some limitations in our study. First, we did not observe the correlation between circulating IL-27, IFN- $\gamma$, IL-10, and circulating mature DC numbers. Second, we did not investigate whether ox-LDL can stimulate other antigenpresenting cells to produce IL-27, such as macrophages and $\mathrm{B}$ cells. Third, we did not directly investigate the effect of IL-27 on DCs in circulation and atherosclerotic plaques and the development of atherosclerosis in vivo. Answering these questions would have helped to better understand the role of IL-27 in patients with CAD.

In conclusion, we found that circulating levels of IL-27 are elevated and closely related to ox-LDL and the severity of coronary atherosclerotic lesions in patients with CAD. We herein provided the evidence that ox-LDL can stimulate DCs to produce IL-27. This study provides further understanding of the pathogenesis of atherosclerosis: elevated IL-27 might be one of the important cytokines that compose a regulatory network in immunity and inflammation to affect atherosclerosis. Further studies are required to elucidate whether IL-27 affects the development and progression of atherosclerosis, which may provide insights into novel therapeutic targets for controlling CAD.

\section{References}

[1] G. F. Anderson and E. Chu, "Expanding priorities-Confronting chronic disease in countries with low income," The New England Journal of Medicine, vol. 356, no. 3, pp. 209-211, 2007.

[2] G. K. Hansson and A. Hermansson, "The immune system in atherosclerosis," Nature Immunology, vol. 12, no. 3, pp. 204$212,2011$.

[3] O. Joffre, M. A. Nolte, R. Spörri, and C. R. E. Sousa, "Inflammatory signals in dendritic cell activation and the induction of adaptive immunity," Immunological Reviews, vol. 227, no. 1, pp. 234-247, 2009.

[4] R. Kushwah and J. Hu, "Complexity of dendritic cell subsets and their function in the host immune system," Immunology, vol. 133, no. 4, pp. 409-419, 2011.

[5] G. J. Adema, "Dendritic cells from bench to bedside and back," Immunology Letters, vol. 122, no. 2, pp. 128-130, 2009.

[6] M. I. Cybulsky and J. Jongstra-Bilen, "Resident intimal dendritic cells and the initiation of atherosclerosis," Current Opinion in Lipidology, vol. 21, no. 5, pp. 397-403, 2010.

[7] A. Niessner and C. M. Weyand, "Dendritic cells in atherosclerotic disease," Clinical Immunology, vol. 134, no. 1, pp. 25-32, 2010.

[8] E. K. Koltsova and K. Ley, "How dendritic cells shape atherosclerosis," Trends in Immunology, vol. 32, no. 11, pp. 540-547, 2011.

[9] J. Andersson, P. Libby, and G. K. Hansson, "Adaptive immunity and atherosclerosis," Clinical Immunology, vol. 134, no. 1, pp. 33-46, 2010.

[10] S. Taleb, A. Tedgui, and Z. Mallat, "Adaptive T cell immune responses and atherogenesis," Current Opinion in Pharmacology, vol. 10, no. 2, pp. 197-202, 2010. 
[11] X. Lu, D. Lu, U. Narayan, and V. V. Kakkar, "The role of Thelper cells in atherosclerosis," Cardiovascular and Hematological Agents in Medicinal Chemistry, vol. 9, no. 1, pp. 25-41, 2011.

[12] C. A. Hunter, "New IL-12-family members: IL-23 and IL27, cytokines with divergent functions," Nature Reviews Immunology, vol. 5, no. 7, pp. 521-531, 2005.

[13] O. Devergne, M. Hummel, H. Koeppen et al., "A novel interleukin-12 p40-related protein induced by latent EpsteinBarr virus infection in B lymphocytes," Journal of Virology, vol. 70, no. 2, pp. 1143-1153, 1996.

[14] S. Pflanz, J. C. Timans, J. Cheung et al., "IL-27, a heterodimeric cytokine composed of EBI3 and p28 protein, induces proliferation of naive $\mathrm{CD}^{+}{ }^{+} \mathrm{T}$ cells," Immunity, vol. 16, no. 6, pp. 779-790, 2002.

[15] S. Pflanz, L. Hibbert, J. Mattson et al., "WSX-1 and Glycoprotein 130 Constitute a Signal-Transducing Receptor for IL-27," Journal of Immunology, vol. 172, no. 4, pp. 2225-2231, 2004.

[16] Q. Chen, N. Ghilardi, H. Wang et al., "Development of Th1type immune responses requires the type I cytokine receptor TCCR," Nature, vol. 407, no. 6806, pp. 916-920, 2000.

[17] C. A. Sprecher, F. J. Grant, J. W. Baumgartner et al., "Cloning and characterization of a novel class I cytokine receptor," Biochemical and Biophysical Research Communications, vol. 246, no. 1, pp. 82-90, 1998.

[18] H. Yoshida, S. Hamano, G. Senaldi et al., "WSX-1 is required for the initiation of Th1 responses and resistance to L. major infection," Immunity, vol. 15, no. 4, pp. 569-578, 2001.

[19] H. Yoshida, M. Nakaya, and Y. Miyazaki, "Interleukin 27: a double-edged sword for offense and defense," Journal of Leukocyte Biology, vol. 86, no. 6, pp. 1295-1303, 2009.

[20] K. S. Stamatelopoulos, J. P. Lekakis, P. Tseke et al., "Differential associations of renal function with coronary and peripheral atherosclerosis," International Journal of Cardiology, vol. 135, no. 2, pp. 162-164, 2009.

[21] H. F. Alber, C. Duftner, M. Wanitschek et al., "Neopterin, $\mathrm{CD} 4{ }^{+} \mathrm{CD} 28^{-}$lymphocytes and the extent and severity of coronary artery disease," International Journal of Cardiology, vol. 135, no. 1, pp. 27-35, 2009.

[22] R. Zaguri, I. Verbovetski, M. Atallah et al., "'Danger' effect of low-density lipoprotein (LDL) and oxidized LDL on human immature dendritic cells," Clinical and Experimental Immunology, vol. 149, no. 3, pp. 543-552, 2007.

[23] N. Johnston, T. Jernberg, B. Lagerqvist, A. Siegbahn, and L. Wallentin, "Oxidized low-density lipoprotein as a predictor of outcome in patients with unstable coronary artery disease," International Journal of Cardiology, vol. 113, no. 2, pp. 167173, 2006.

[24] G. K. Hansson, "Mechanisms of disease: inflammation, atherosclerosis, and coronary artery disease," The New England Journal of Medicine, vol. 352, no. 16, pp. 1685-1626, 2005.

[25] A. Takeda, S. Hamano, A. Yamanaka et al., "Cutting edge: role of IL-27/WSX-1 signaling for induction of T-bet through activation of STAT1 during initial Th1 commitment," Journal of Immunology, vol. 170, no. 10, pp. 4886-4890, 2003.

[26] D. Artis, A. Villarino, M. Silverman et al., "The IL-27 receptor (WSX-1) is an inhibitor of innate and adaptive elements of type 2 immunity," Journal of Immunology, vol. 173, no. 9, pp. 5626-5634, 2004.

[27] T. Yoshimoto, T. Yoshimoto, K. Yasuda, J. Mizuguchi, and K. Nakanishi, "IL-27 suppresses Th2 cell development and Th2 cytokines production from polarized Th2 cells: a novel therapeutic way for Th2-mediated allergic inflammation," Journal of Immunology, vol. 179, no. 7, pp. 4415-4423, 2007.

[28] M. Batten, J. Li, S. Yi et al., "Interleukin 27 limits autoimmune encephalomyelitis by suppressing the development of interleukin 17-producing T cells," Nature Immunology, vol. 7, no. 9, pp. 929-936, 2006.

[29] J. S. Stumhofer, A. Laurence, E. H. Wilson et al., "Interleukin 27 negatively regulates the development of interleukin 17producing $\mathrm{T}$ helper cells during chronic inflammation of the central nervous system," Nature Immunology, vol. 7, no. 9, pp. 937-945, 2006.

[30] S. Hamano, K. Himeno, Y. Miyazaki et al., "WSX-1 is required for resistance to Trypanosoma cruzi infection by regulation of proinflammatory cytokine production," Immunity, vol. 19, no. 5, pp. 657-667, 2003.

[31] A. Villarino, L. Hibbert, L. Lieberman et al., "The IL-27R (WSX-1) is required to suppress $\mathrm{T}$ cell hyperactivity during infection," Immunity, vol. 19, no. 5, pp. 645-655, 2003.

[32] A. Awasthi, Y. Carrier, J. P. S. Peron et al., "A dominant function for interleukin 27 in generating interleukin 10producing anti-inflammatory T cells," Nature Immunology, vol. 8, no. 12, pp. 1380-1389, 2007.

[33] S. A. Summers, R. K. S. Phoon, J. D. Ooi, S. R. Holdsworth, and A. R. Kitching, "The IL-27 receptor has biphasic effects in crescentic glomerulonephritis mediated through Th1 responses," American Journal of Pathology, vol. 178, no. 2, pp. 580-590, 2011.

[34] J. Siebler, S. Wirtz, C. Frenzel et al., "Cutting edge: a key pathogenic role of IL-27 in T cell-mediated hepatitis," Journal of Immunology, vol. 180, no. 1, pp. 30-33, 2008.

[35] E. E. S. Nieuwenhuis, M. F. Neurath, N. Corazza et al., "Disruption of $\mathrm{T}$ helper 2-immune responses in EpsteinBarr virus-induced gene 3-deficient mice," Proceedings of the National Academy of Sciences of the United States of America, vol. 99, no. 26, pp. 16951-16956, 2002.

[36] A. Yoshizaki, K. Yanaba, Y. Iwata et al., "Elevated serum interleukin-27 levels in patients with systemic sclerosis: association with T cell, B cell and fibroblast activation," Annals of the Rheumatic Diseases, vol. 70, no. 1, pp. 194-200, 2011.

[37] R. Rajaiah, M. Puttabyatappa, S. K. Polumuri, and K. D. Moudgil, "Interleukin-27 and interferon- $\gamma$ are involved in regulation of autoimmune arthritis," Journal of Biological Chemistry, vol. 286, no. 4, pp. 2817-2825, 2011.

[38] Y. Miyazaki, H. Inoue, M. Matsumura et al., "Exacerbation of experimental allergic asthma by augmented Th2 responses in WSX-1-deficient mice," Journal of Immunology, vol. 175, no. 4, pp. 2401-2407, 2005.

[39] H. Fujita, A. Teng, R. Nozawa et al., "Production of both IL27 and IFN- $\gamma$ after the treatment with a ligand for invariant NK T cells is responsible for the suppression of $\mathrm{TH} 2$ response and allergic inflammation in a mouse experimental asthma model," Journal of Immunology, vol. 183, no. 1, pp. 254-260, 2009.

[40] M. Batten, J. Li, S. Yi et al., "Interleukin 27 limits autoimmune encephalomyelitis by suppressing the development of interleukin 17-producing T cells," Nature Immunology, vol. 7, no. 9, pp. 929-936, 2006.

[41] D. C. Fitzgerald, B. Ciric, T. Touil et al., "Suppressive effect of IL-27 on encephalitogenic Th17 cells and the effector phase of experimental autoimmune encephalomyelitis," Journal of Immunology, vol. 179, no. 5, pp. 3268-3275, 2007. 
[42] D. C. Fitzgerald, G. X. Zhang, M. El-Behi et al., "Suppression of autoimmune inflammation of the central nervous system by interleukin 10 secreted by interleukin 27 -stimulated T cells," Nature Immunology, vol. 8, no. 12, pp. 1372-1379, 2007.

[43] Y. S. Lee, A. Amadi-Obi, C. R. Yu, and C. E. Egwuagu, "Retinal cells suppress intraocular inflammation (uveitis) through production of interleukin-27 and interleukin-10," Immunology, vol. 132, no. 4, pp. 492-502, 2011.

[44] L. E. Rosas, A. A. Satoskar, K. M. Roth et al., "Interleukin-27R (WSX-1/T-cell cytokine receptor) gene-deficient mice display enhanced resistance to Leishmania donovani infection but develop severe liver immunopathology," American Journal of Pathology, vol. 168, no. 1, pp. 158-169, 2006.

[45] R. M. Steinman and Z. A. Cohn, "Identification of a novel cell type in peripheral lymphoid organs of mice. I. Morphology, quantitation, tissue distribution," Journal of Experimental Medicine, vol. 137, no. 5, pp. 1142-1162, 1973.

[46] M. Rossi and J. W. Young, "Human dendritic cells: potent antigen-presenting cells at the crossroads of innate and adaptive immunity," Journal of Immunology, vol. 175, no. 3, pp. 1373-1381, 2005.

[47] Y. V. Bobryshev, "Dendritic cells and their role in atherogenesis," Laboratory Investigation, vol. 90, no. 7, pp. 970-984, 2010.

[48] E. A. Van Vré, V. Y. Hoymans, H. Bult et al., "Decreased number of circulating plasmacytoid dendritic cells in patients with atherosclerotic coronary artery disease," Coronary Artery Disease, vol. 17, no. 3, pp. 243-248, 2006.

[49] A. Yilmaz, J. Weber, I. Cicha et al., "Decrease in circulating myeloid dendritic cell precursors in coronary artery disease," Journal of the American College of Cardiology, vol. 48, no. 1, pp. 70-80, 2006.

[50] I. Van Brussel, E. A. Van Vré, G. R. Y. De Meyer, C. J. Vrints, J. M. Bosmans, and H. Bult, "Decreased numbers of peripheral blood dendritic cells in patients with coronary artery disease are associated with diminished plasma Flt3 ligand levels and impaired plasmacytoid dendritic cell function," Clinical Science, vol. 120, no. 9, pp. 415-426, 2011.

[51] W. Su, A. Sun, D. Xu et al., "Tongxinluo inhibits oxidized lowdensity lipoprotein-induced maturation of human dendritic cells via activating peroxisome proliferator-activated receptor gamma pathway," Journal of Cardiovascular Pharmacology, vol. 56, no. 2, pp. 177-183, 2010.

[52] M. M. Ramadan, M. Kodama, S. Hirono et al., "Evaluation of oxidized low-density lipoprotein in the coronary circulation of patients with coronary artery disease, and its association with percutaneous coronary intervention," International Journal of Cardiology, vol. 134, no. 3, pp. e117-e119, 2009.

[53] Y. Ishigaki, Y. Oka, and H. Katagiri, "Circulating oxidized LDL: a biomarker and a pathogenic factor," Current Opinion in Lipidology, vol. 20, no. 5, pp. 363-369, 2009.

[54] H. Itabe, T. Obama, and R. Kato, "The dynamics of oxidized LDL during atherogenesis," Journal of Lipid, vol. 2011, Article ID 418313, 9 pages, 2011.

[55] H. Ait-Oufella, S. Taleb, Z. Mallat, and A. Tedgui, "Recent advances on the role of cytokines in atherosclerosis," Arteriosclerosis, Thrombosis, and Vascular Biology, vol. 31, no. 5, pp. 969-979, 2011.

[56] Y. V. Bobryshev and R. S. A. Lord, "Ultrastructural recognition of cells with dendritic cell morphology in human aortic intima. Contacting interactions of vascular dendritic cells in athero-resistant and athero-prone areas of the normal aorta,"
Archives of Histology and Cytology, vol. 58, no. 3, pp. 307-322, 1995.

[57] K. E. Paulson, S. N. Zhu, M. Chen, S. Nurmohamed, J. Jongstra-Bilen, and M. I. Cybulsky, "Resident intimal dendritic cells accumulate lipid and contribute to the initiation of atherosclerosis," Circulation Research, vol. 106, no. 2, pp. 383390, 2010.

[58] J. Jongstra-Bilen, M. Haidari, S. N. Zhu, M. Chen, D. Guha, and M. I. Cybulsky, "Low-grade chronic inflammation in regions of the normal mouse arterial intima predisposed to atherosclerosis," Journal of Experimental Medicine, vol. 203, no. 9, pp. 2073-2083, 2006.

[59] P. Liu, Y. R. A. Yu, J. A. Spencer et al., "CX3CR1 deficiency impairs dendritic cell accumulation in arterial intima and reduces atherosclerotic burden," Arteriosclerosis, Thrombosis, and Vascular Biology, vol. 28, no. 2, pp. 243-250, 2008.

[60] A. Yilmaz, M. Lochno, F. Traeg et al., "Emergence of dendritic cells in rupture-prone regions of vulnerable carotid plaques," Atherosclerosis, vol. 176, no. 1, pp. 101-110, 2004.

[61] Y. V. Bobryshev and R. S. A. Lord, "Co-accumulation of dendritic cells and natural killer $\mathrm{T}$ cells within ruptureprone regions in human atherosclerotic plaques," Journal of Histochemistry and Cytochemistry, vol. 53, no. 6, pp. 781-785, 2005.

[62] I. Kawahara, N. Kitagawa, K. Tsutsumi, I. Nagata, T. Hayashi, and T. Koji, "The expression of vascular dendritic cells in human atherosclerotic carotid plaques," Human Pathology, vol. 38, no. 9, pp. 1378-1385, 2007.

[63] C. Erbel, K. Sato, F. B. Meyer et al., "Functional profile of activated dendritic cells in unstable atherosclerotic plaque," Basic Research in Cardiology, vol. 102, no. 2, pp. 123-132, 2007.

[64] E. A. Van Vré, J. M. Bosmans, I. Van Brussel et al., "Immunohistochemical characterisation of dendritic cells in human atherosclerotic lesions: possible pitfalls," Pathology, vol. 43, no. 3, pp. 239-247, 2011. 


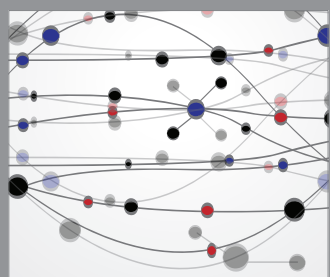

The Scientific World Journal
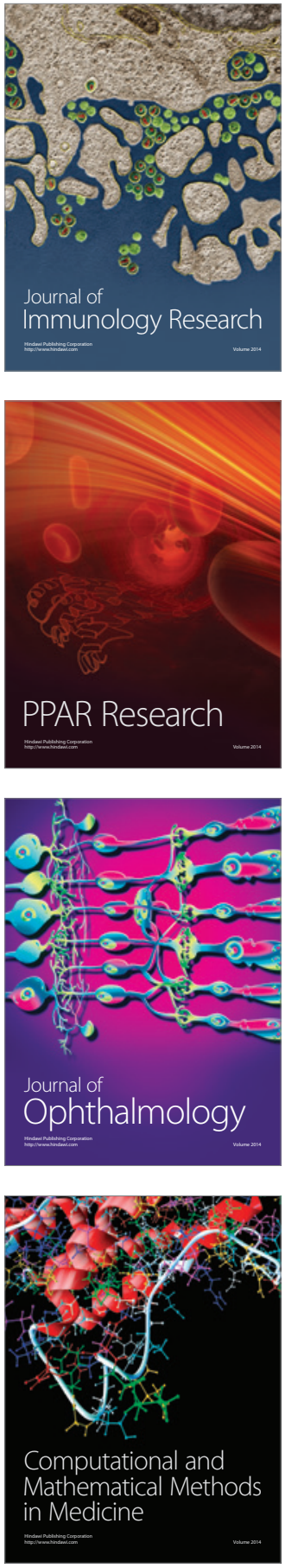

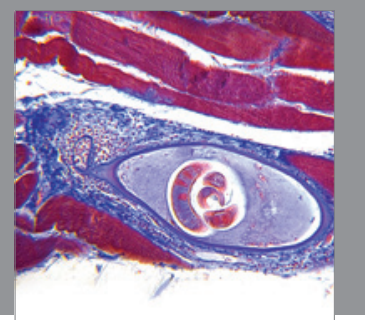

Gastroenterology

Research and Practice
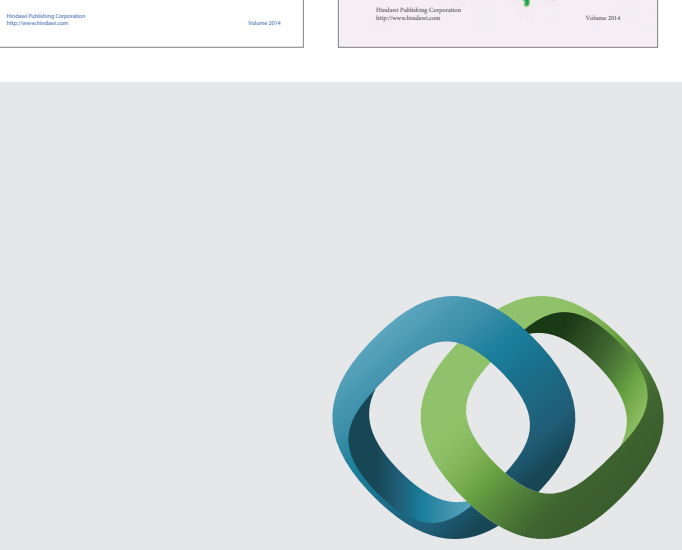

\section{Hindawi}

Submit your manuscripts at

http://www.hindawi.com
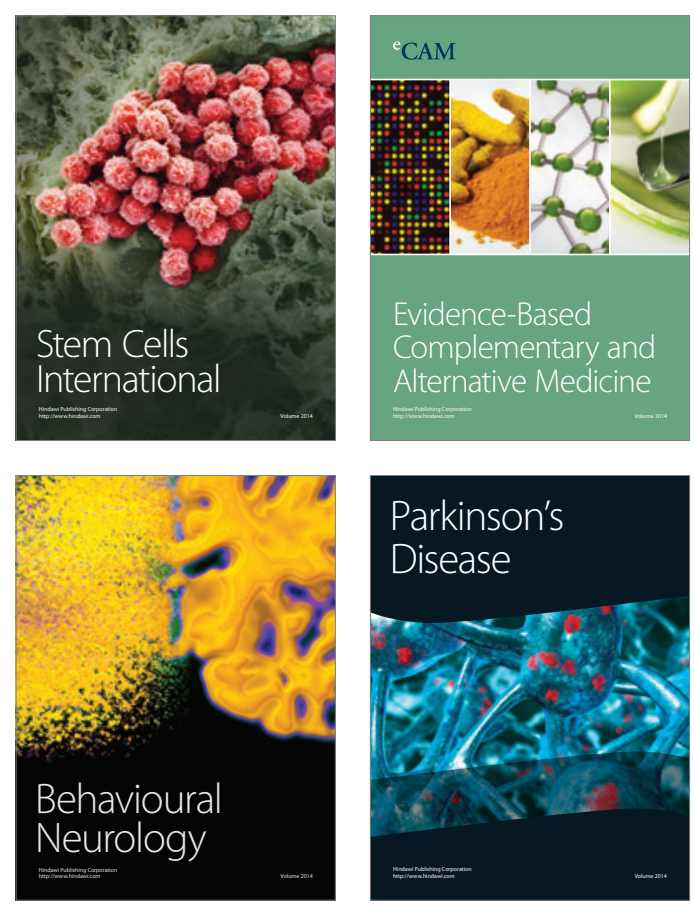

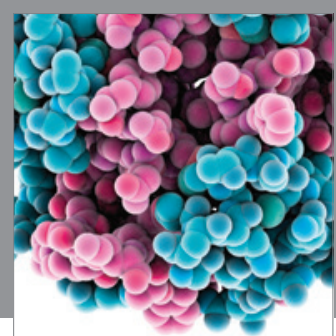

Journal of
Diabetes Research

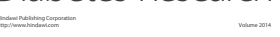

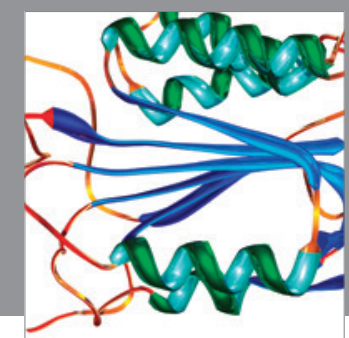

Disease Markers
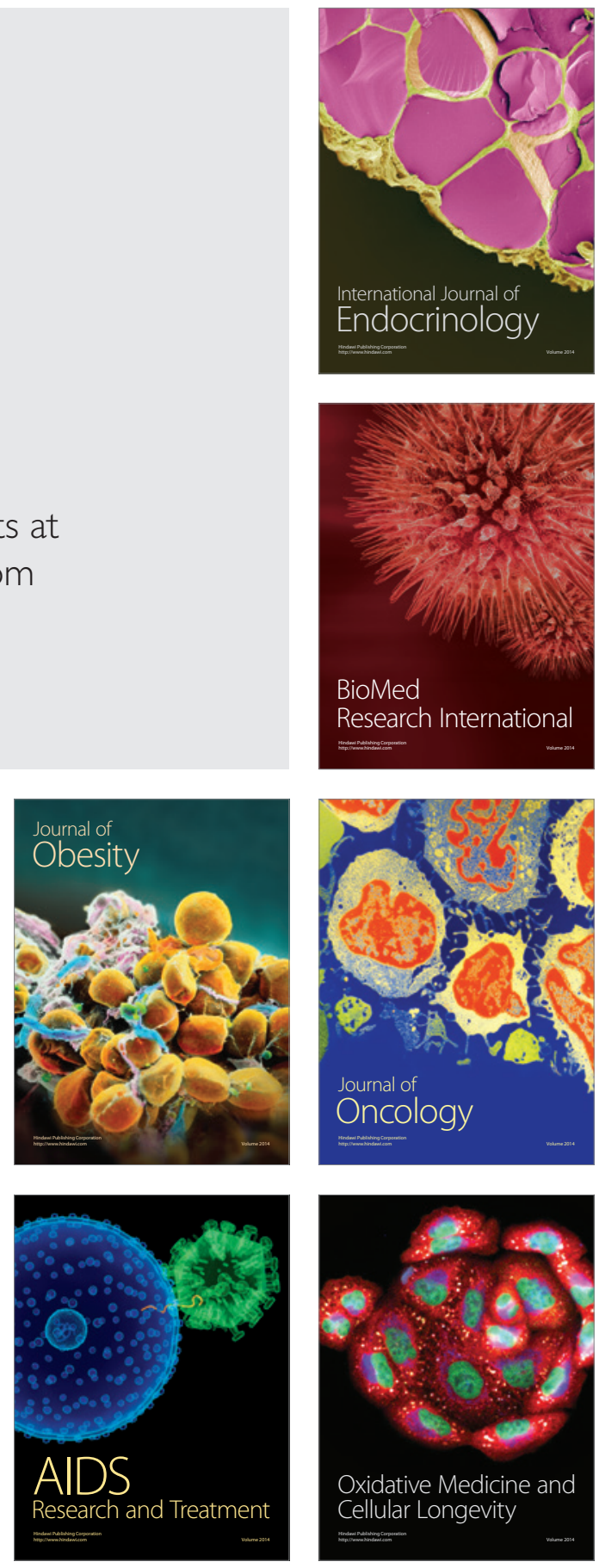